\title{
Optical nonlinearity in measurement of urea and uric acid in blood
}

\author{
A. N. Dhinaa, P. K. Palanisamy
}

Department of Physics, Anna University Chennai, Chennai, India; profpkpannauniv@yahoo.co.in

Received 23 November 2009; revised 15 December 2009; accepted 30 December 2009.

\begin{abstract}
The Z-scan technique is a simple and effective tool for determining nonlinear optical properties of materials. This technique is utilized in measurement of urea and uric acid in blood. The nonlinear refractive index of urea and uric acid are found to vary linearly with concentration. Hence by calculating the nonlinear refractive index it is possible to measure their concentration in the sample. The results of this method are found to be in good agreement with the conventional colorimetric method.
\end{abstract}

Keywords: Z-Scan Technique;

Nonlinear Refractive Index; Urea; Uric Acid

\section{INTRODUCTION}

Urea and Uric acid are the metabolic nitrogenous wastes present in the body that can be measured in blood and urine. Serum uric acid reflects the interactions of four major processes: dietary purine intake, endogenous purine metabolism, urinary urate excretion, and intestinal uricolysis. Uric acid is a metabolite of purines, nucleic acids and nucleoproteins. Consequently, abnormal levels may be indicative of a disorder in the metabolism of these substances. Hyperuricaemia may be observed in renal dysfunction, gout, leukemia, polycythaemia, atherosclerosis, diabetes, hypothyroidism, or in some genetic diseases. Decreased levels are present in patients with Wilson's disease and Fanconis syndrome [1]. The existing methods could be conveniently divided into two groups: reductive and enzymatic. The reductive methods are non-specific and involve the oxidation of uric acid with phosphotungstate reagent to allantoin with resultant blue coloring of tungstate solution.

The enzymatic methods are specific. They involve the catalytic oxidation of uric acid with the enzyme uricase to allantoin with the formation of hydrogen peroxide [2]. The peroxide concentration which is directly proportional to the concentration of uric acid could then be determined by a number of methods [3-11]. The amount of urea nitrogen is a breakdown product of protein metabolism. Urea formed in the liver as the end product of protein metabolism enters in to the blood and is ultimately eliminated in the urine by the kidneys. Most kidney diseases affect urea excretion so that blood urea nitrogen (BUN) levels increase in the blood. It may also increase the dehydration or bleeding in the stomach and/or intestines or result in any side effect of some medications. Raised levels may also be seen in any state causing hypovolemia, heart failure, starvation and urinary tract obstruction, etc. Urea is one of the first substances to be determined in biological fluids as one of the parameters of liver function tests. In routine procedures urea determination in biological fluids is carried out with chemical reagents and enzymatic methods $[12,13]$.

The Z-scan technique was extending to study the optical nonlinearity of vitreous humor in human and rabbit [14], retinal derivatives [15]. In this present investigation enzymatic reacted urea and uric acid blood sample are subjected to the Z-scan technique to calculate the nonlinear refractive index $\left(\mathrm{n}_{2}\right)$. Already work has been done on measurement of glucose [16], total cholesterol and triglycerides [17].

The single beam Z-scan analysis, which was developed by Mansoor Sheik Bahae et al. [18], is a simple and effective tool for determining nonlinear optical properties of materials [19-22]. Nonlinear refractive index is proportional to the real part of the third-order susceptibility $\operatorname{Re}\left[x^{(3)}\right]$. Basically, the Z-scan method consists in translating a nonlinear sample through the focal plane of a tightly focused Gaussian laser beam and monitoring the changes in the far field intensity pattern. For a purely refractive nonlinearity, the light field induces an intensity dependent nonlinear phase and, as consequence of the transverse Gaussian intensity profile, the sample presents a lens-like behavior. The induced self-phase modulation has the tendency of defocusing or re-collimating the incident beam, depending on its $Z$ position with respect to the focal plane. By monitoring the transmittance change through a small circular aperture placed 
at the far field position, it is possible to determine the nonlinear refractive index. In this present study, we have measured urea and uric acid levels in blood by calculating the nonlinear refractive index $\left(\mathrm{n}_{2}\right)$ value using a single beam Z-scan method.

\section{EXPERIMENTAL}

\subsection{Urea Sample Preparation}

For sample preparation (Urea by Berthelot method - a kit supplied by Aspen Laboratories, Baddi, Himachal Pradesh, India) was used. To $10 \mu \mathrm{l}$ of the serum first 50 $\mu l$ of urease enzyme was added and incubated for $5 \mathrm{~min}$ utes at $37^{\circ} \mathrm{C}$. Then $1.5 \mathrm{ml}$ of phenol reagent and $1.5 \mathrm{ml}$ of hypochlorite reagent were added and incubated for 20 minutes at $37^{\circ} \mathrm{C}$. The principles involved for this reaction are follows:

$$
\begin{aligned}
& \text { Urea }+\mathrm{H}_{2} \mathrm{O} \underset{\text { Urease }}{\stackrel{\text { Ammonia }}{\longrightarrow} \text { Phenol }+ \text { Hypochlorite }} \text { Ammonia }+\mathrm{CO}_{2} \\
& \stackrel{\text { Nitropruside }}{\longrightarrow} \text { Indophenol }
\end{aligned}
$$

Urease hydrolyses urea into ammonia and carbon dioxide. In alkaline conditions, ammonia reacts with hypochlorite and phenol in the presence of nitropruside to form Indophenol colored complex. The intensity of the color is directly proportional to the concentration of urea in the sample.

\subsection{Uric Acid Sample Preparation}

$1 \mathrm{ml}$ of uricase enzyme was added to $20 \mu \mathrm{l}$ of serum (Uricase based on POD - a kit supplied by Merck, Mumbai, India). The solution was mixed well and incubated at $37^{\circ} \mathrm{C}$ for 10 minutes. The principle involved in this reaction is represented as:

$$
\begin{array}{r}
\text { Uric acid }+\mathrm{H}_{2} \mathrm{O}+\mathrm{O}_{2} \underset{\text { Uricase }}{\longrightarrow} \text { Allantoin }+\mathrm{CO}_{2}+\mathrm{H}_{2} \mathrm{O}_{2} \\
\text { 4- Aminoantipyrine }+ \text { TBHBA }+2 \mathrm{H}_{2} \mathrm{O}_{2} \\
\stackrel{\text { POD }}{\longrightarrow} \text { Quinoneimine dye }+3 \mathrm{H}_{2} \mathrm{O}
\end{array}
$$

Uric acid is hydrolyzed by Uricase to allontoin and hydrogen peroxide. Hydrogen peroxide so formed reacts with 4-aminoantipyrine and 2, 4, 6-tribromo-3- hydroxy benzoic acid (TBHBA) in the presence of enzyme peroxidase (POD) to produce Quinoneimine dye compound. The intensity of the color is directly proportional to the concentration of uric acid in the sample.

\subsection{Nonlinearity Measurements}

Z-scan experiments were performed using a $532 \mathrm{~nm} \mathrm{Nd}$ : YAG (SHG) CW laser beam (COHERENT -Compass 215M-50 diode-pumped laser) focused by a lens of 35 $\mathrm{mm}$ focal length. The experimental set up is shown in

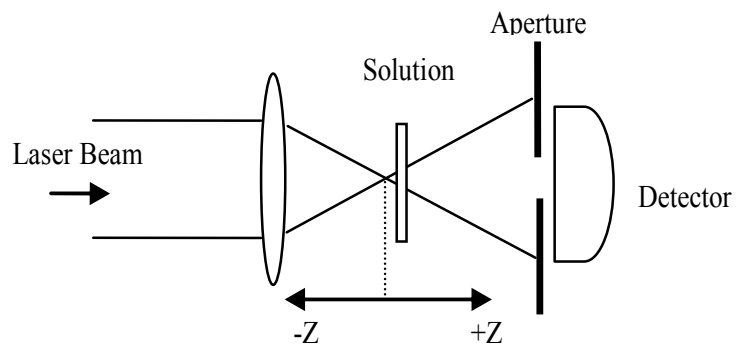

Figure 1. Experimental setup for Z-scan technique.

Figure 1. A typical closed-aperture Z-scan curves for the standard urea and uric acid solution at incident intensity $\mathrm{I}_{\mathrm{o}}=7.824 \mathrm{~kW} / \mathrm{cm}^{2}$, are shown in Figure 3. This normalized transmittance curves are characterized by a pre-focal peak followed by a post-focal valley. This implies that the nonlinear refractive indices of urea, uric acid are negative $\left(\mathrm{n}_{2}<0\right)$. The defocusing effect shown in Z- scan curve can be attributed to a thermal nonlinearity resulting from absorption of radiation at $532 \mathrm{~nm}$. Localized absorption of a tightly focused beam propagating through an absorbing sample medium produces a spatial distribution of temperature in the sample solution and consequently, a spatial variation of the refractive index, that acts as a thermal lens resulting in phase distortion of the propagating beam.

The nonlinear refractive index $\left(\mathrm{n}_{2}\right)$ is calculated using the standard relations [18].

$$
\Delta T_{p-v}=0.406(1-S)^{0.25}\left|\Delta \Phi_{0}\right|
$$

where $\Delta T_{p-v}$ can be defined as the difference between the normalized peak and valley transmittances $\left(T_{p}-T_{v}\right)$, | $\Delta \Phi_{0} \mid$ is the on-axis phase shift at the focus.

The linear transmittance of the aperture is given by

$$
S=1-\exp \left(-2 r_{a}^{2} / w_{a}^{2}\right)
$$

where $r_{a}$ is the radius of the aperture and $w_{a}$ is the beam radius at the aperture.

$$
n_{2} \approx \frac{\Delta \Phi_{0}}{k I_{0} L_{e f f}}
$$

where $\mathrm{n}_{2}$ is the nonlinear refractive index, $\mathrm{k}$ is the wave number $\left(k=\frac{2 \pi}{\lambda}\right)$ and

$$
L_{e f f}=\frac{1-e^{-\alpha L}}{\alpha}
$$

$I_{0}=\frac{2 P}{\pi w_{0}{ }^{2}}$ is defined as the peak intensity within the sample at the focus. $L$ is the thickness of the sample, $\alpha$ is the linear absorption coefficient.

The results are checked by performing conventional colorimetric method following the standard procedure of 

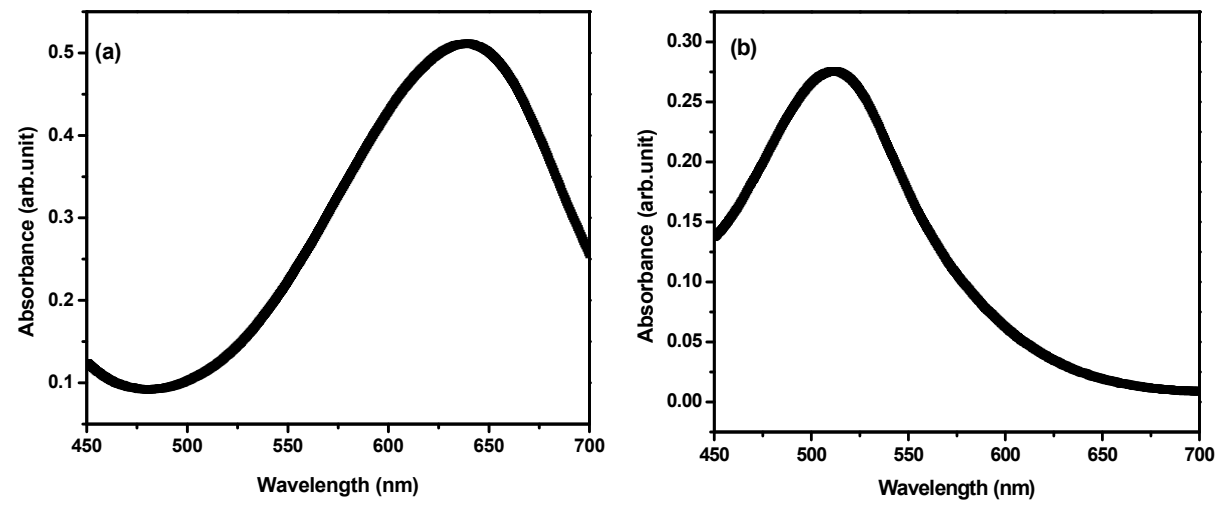

Figure 2. UV-Vis Spectra of standard (a) urea (b) uric acid with reagent.
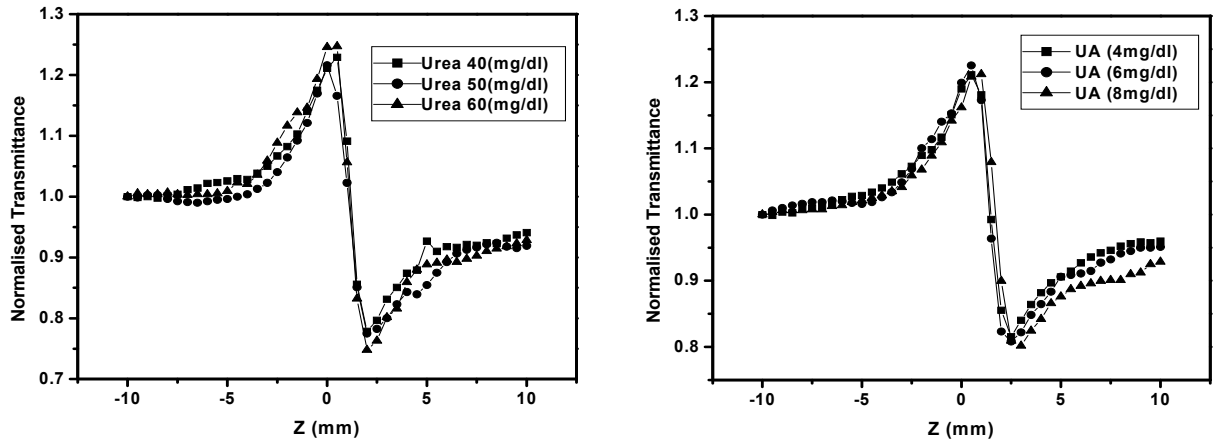

Figure 3. Z-scan data of the standard urea and uric acid (UA).
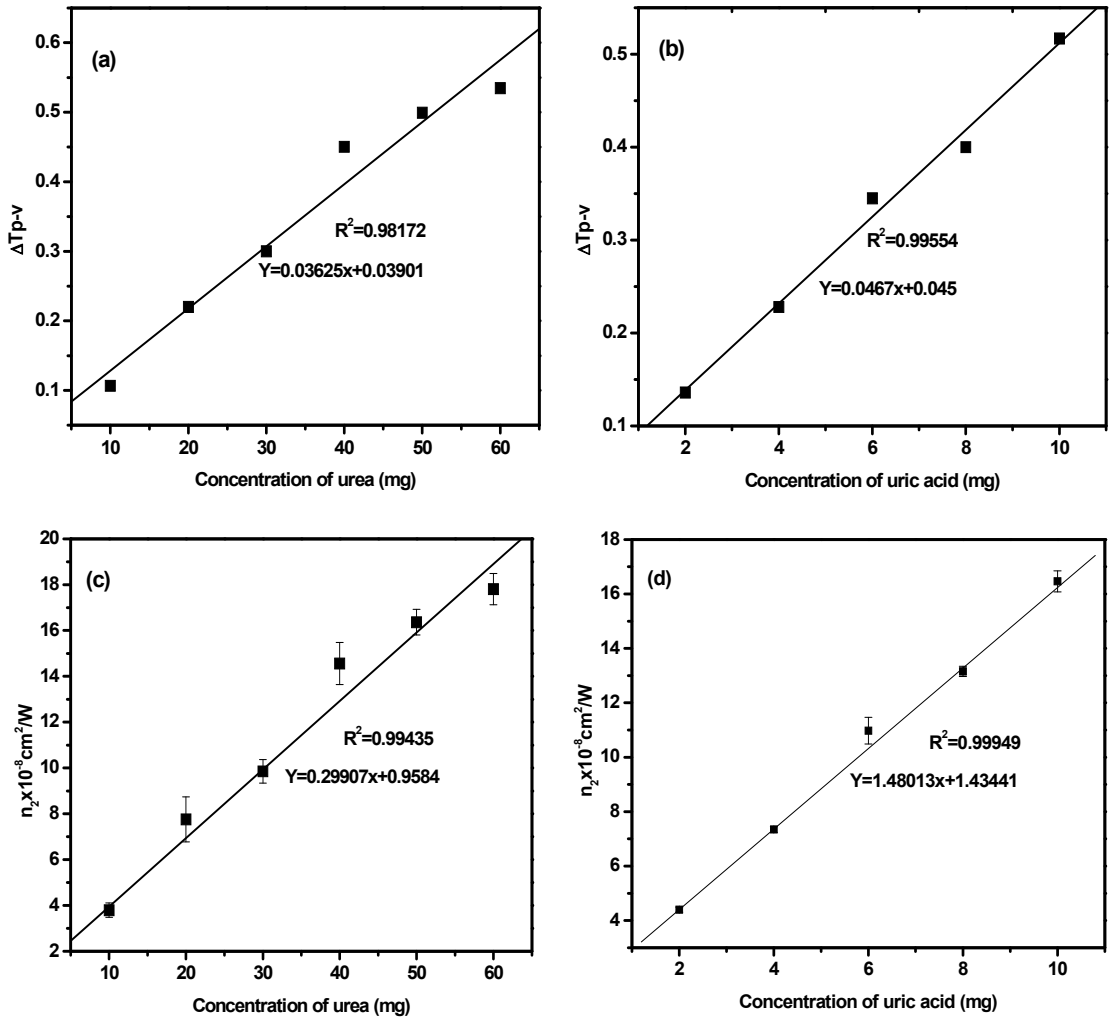

Figure 4. Linear variation of $\mathrm{T} p-\mathrm{v}$ and nonlinear refractive index $\left(\mathrm{n}_{2}\right)$ with concentration of urea $(\mathrm{a}, \mathrm{c})$ and uric acid $(\mathrm{b}, \mathrm{d})$ by Z-scan method. 

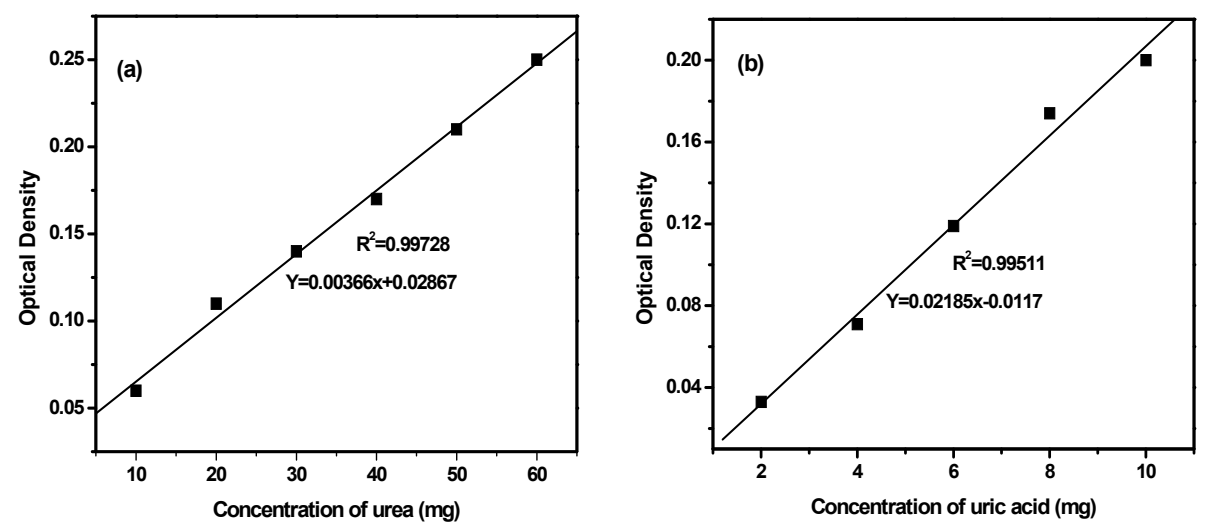

Figure 5. Linear variation of optical density of urea (a) and uric acid (b) by colorimetric method.

A. J. Taylor et al. [23] for urea and P. Fossati et al. [24] for uric acid. This involves measurement of optical density variation with respect to concentration as shown in Figure 5. The results thus obtained are compared with the results calculated with the Z-scan technique.

\subsection{Statistical Analysis}

The error involved in the measurements was determined by $t$ test, $P<0.01$. These statistical analysis was conducted using SPSS commercial statistical package (SPSS, version 10.0 for windows, SPSS Inc., Chicago, U.S.A).

\section{RESULTS AND DISCUSSION}

\subsection{Spectral Absorbance Measurements}

The absorption spectra were measured using UV-Vis spectrophotometer (SHIMADZU-UV-2401PC), and the spectra for both urea and uric acid were found to be broad banded as depicted in Figure 2. Both have exhibited good absorption at $532 \mathrm{~nm}$. Hence for further study $532 \mathrm{~nm}$ Nd: YAG laser was used.

\subsection{Nonlinear Refractive Index}

The results of typical Z-scan normalized transmittance measurement for urea and uric acid are shown in Figure 3. As the concentration of the standard urea and uric acid increases, the normalized transmittance peak increases whereas the valley decreases respectively.

It is found that $\Delta \mathrm{T}_{\mathrm{p}-\mathrm{v}}$ as well as refractive index value increase linearly with concentration of standard urea and uric acid as seen in Figure 4(a) to (d). Figure 5(a) and (b) shows the linear variation of optical density with concentration of urea and uric acid respectively as measured with conventional colorimetric method.

The experiments were repeated five times and the mean value of the nonlinear refractive index $\left(\mathrm{n}_{2}\right)$ was calculated from the normalized transmittance values. This calculated value was assumed to be the standard for measurement of unknown urea and uric acid content pre- sent in blood sample. This was arrived by plotting a linear graph of urea and uric acid concentration Vs non- linear refractive index. The nonlinear refractive index value was first measured against the reagent blank solution.

The calibration was made with the conventional colorimetric method and the results are tabulated in Table 1 for urea and Table 3 for uric acid. The common urea level in blood serum is $10-50 \mathrm{mg} / \mathrm{dl}$. The common uric acid level in blood serum is $3.4-7.0 \mathrm{mg} / \mathrm{dl}$ range for Males and 2.5-6.0 mg/dl range for Females.

To calculate the urea and uric acid levels, one need not

Table 1. Nonlinear refractive index $\left(\mathrm{n}_{2}\right)$ values for standard urea.

\begin{tabular}{cc}
\hline $\begin{array}{c}\text { Standard Urea } \\
\text { Concentration }(\mathrm{mg} / \mathrm{dl})\end{array}$ & $\begin{array}{c}\text { Nonlinear refractive index } \\
\mathrm{n}_{2} \times 10^{-8}\left(\mathrm{~cm}^{2} / \mathrm{W}\right)\end{array}$ \\
\hline 10 & $03.79 \pm 0.31$ \\
20 & $07.75 \pm 0.98$ \\
30 & $09.85 \pm 0.51$ \\
40 & $14.55 \pm 0.91$ \\
50 & $16.36 \pm 0.55$ \\
60 & $17.80 \pm 0.68$ \\
\hline
\end{tabular}

Table 2. Comparative analysis of serum urea measurement using colorimetric method and Z-scan method.

\begin{tabular}{cccc}
\hline \multirow{2}{*}{$\begin{array}{c}\text { Sample } \\
\text { Collection }\end{array}$} & Urea level & \multicolumn{2}{c}{ Concentration of urea (mg/dl) } \\
\cline { 3 - 4 } & & $\begin{array}{c}\text { Colorimetric } \\
\text { method }\end{array}$ & Z-scan method \\
\hline Male & Normal & 34.74 & 35.08 \\
Female & Normal & 33.82 & 33.12 \\
Male & Normal & 42.82 & 42.24 \\
Female & Normal & 31.46 & 32.03 \\
Female & Normal & 26.64 & 25.85 \\
Male & Normal & 38.08 & 38.99 \\
\hline
\end{tabular}

Each value is the mean of 5 individual observations. The $P$ value (t-test value) is less than 0.01 at $1 \%$ significance level. 
Table 3. Nonlinear refractive index $\left(\mathrm{n}_{2}\right)$ values for standard uric acid.

\begin{tabular}{cc}
\hline $\begin{array}{c}\text { Standard Uric acid } \\
\text { concentration }(\mathrm{mg} / \mathrm{dl})\end{array}$ & $\begin{array}{c}\text { Nonlinear refractive index } \\
\mathrm{n}_{2} \times 10^{-8}\left(\mathrm{~cm}^{2} / \mathrm{W}\right)\end{array}$ \\
\hline 2 & $04.39 \pm 0.09$ \\
4 & $07.34 \pm 0.10$ \\
6 & $10.97 \pm 0.48$ \\
8 & $13.15 \pm 0.18$ \\
10 & $16.46 \pm 0.38$ \\
\hline
\end{tabular}

Table 4. Comparative analysis of serum uric acid measurement using colorimetric method and Z-scan method.

\begin{tabular}{|c|c|c|c|}
\hline \multirow{2}{*}{$\begin{array}{l}\text { Sample } \\
\text { collection }\end{array}$} & \multirow{2}{*}{$\begin{array}{l}\text { Uric acid } \\
\text { level }\end{array}$} & \multicolumn{2}{|c|}{ Concentration of uric acid $(\mathrm{mg} / \mathrm{dl})$} \\
\hline & & $\begin{array}{c}\text { Colorimetric } \\
\text { method }\end{array}$ & Z-scan method \\
\hline Female & Normal & 3.40 & 3.37 \\
\hline Male & Normal & 5.55 & 5.61 \\
\hline Male & Normal & 5.47 & 5.46 \\
\hline Female & Normal & 4.05 & 4.12 \\
\hline Male & Normal & 6.28 & 6.26 \\
\hline Female & Normal & 4.35 & 4.34 \\
\hline
\end{tabular}

Each value is the mean of 5 individual observations. The $P$ value (t-test value) is less than 0.01 at $1 \%$ significance level.

plot full Z-scan curve every time. Once, experimental setup explained above is established, one needs to note down peak and valley values of the transmittance curve translating the sample holder continuously along $\mathrm{Z}$ - axis.

The difference in these two values $T_{p}-T_{v},\left|\Delta \Phi_{0}\right|$ when substituted in Eq.(3) yields the nonlinear refractive index value [17].

From the Z-scan results we infer that, the nonlinear refractive index $\mathrm{n}_{2}$ values for the common level of urea in blood serum $(10-50 \mathrm{mg} / \mathrm{dl})$ are $03.79 \pm 0.31$ and 16.36 $\pm 0.55 \times 10^{-8} \mathrm{~cm}^{2} / \mathrm{W}$ respectively.

Likewise, for common level of uric acid in blood serum for males 3.4-7.0 mg/dl and their corresponding $\mathrm{n}_{2}$ values are 6.45 and $11.78 \times 10^{-8} \mathrm{~cm}^{2} / \mathrm{W}$ respectively. For females $2.5-6.0 \mathrm{mg} / \mathrm{dl}$ and their corresponding $\mathrm{n}_{2}$ values are 5.15 and $10.97 \pm 0.48 \times 10^{-8} \mathrm{~cm}^{2} / \mathrm{W}$ respectively.

\subsection{Evaluation with Conventional Method}

Many trials were performed to measure the urea and uric acid level with our proposed method. The blood samples were collected from six volunteers. (Three males and three female). We could see that the results arrived are in good agreement with those of the conventional colorimetric method for urea Table 2 and for uric acid Table 4. This ascertains that the proposed method is on equality with the conventional colorimetric method.

\section{CONCLUSIONS}

We have measured the nonlinear refractive index values for urea and uric acid present in the serum sample by Z-scan method with $532 \mathrm{~nm} \mathrm{Nd:YAG} \mathrm{CW} \mathrm{laser.} \mathrm{The}$ $\mathrm{Z}$-scan measurements indicate that urea and uric acid in standard sample and blood sample exhibit nonlinear optical properties. Comparative analysis of these values with the one obtained by conventional colorimetric method shows that they are in good agreement. Thus $\mathrm{Z}$-scan technique is found to be suitable for measurement of bioanalytes.

\section{REFERENCES}

[1] Peters, J.P. and Van Slyke, D.D. (1946) Quantitative Clinical Chemistry Interpretations, 1, Williams and Wilkins, Baltimore.

[2] Tietz, N.W. (1986) Textbook of Clinical Chemistry, W.B.Saunders Company, Philadelphia.

[3] Galba'n, J., Andreu, Y., Almenara, M.J., Demarcos, S. and Castillo, J.R. (2001) Direct determination of uric acid in serum by a fluorometric-enzymatic method based on uricase. Talanta, 54, 847-854.

[4] Matos, R.C., Augelli, M.A., Lago, C.L. and Angnes, L. (2000) Flow injection analysis-amperometric determination of ascorbic and uric acids in urine using arrays of gold microelectrodes modified by electrodeposition of palladium. Analytica Chimica Acta, 404, 151-157.

[5] Nakaminami, T., Ito, S.-I., Kuwabata, S. and Yoneyama, H. (1999) Uricase-catalyzed oxidation of uric acid using an artificial electron acceptor and fabrication of amperometric uric acid sensors with use of a redox ladder polymer. Analytical Chemistry, 71, 1928-1934.

[6] Hasebe, Y., Nawa, K., Ujita, S. and Uchiyama, S. (1998) Highly sensitive flow detection of uric acid based on an intermediate regeneration of uricase. Analyst, 123, 17751780.

[7] Kayamori, Y., Katayama, Y., Matsuyama, T. and Urata, T. (1997) Enzymatic method for assaying uric acid in serum with a new tetrazolium salt produces water-soluble formazan dye. Clinical Biochemistry, 30, 595-599.

[8] Miland, E., Ordieres, A.J.M., Blanco, P.T. and Smyth, M.R. (1996) Poly(o-aminophenol) modified bienzyme carbon paste electrode for the detection of uric acid. $\mathrm{Ta}$ lanta, 43, 785-796.

[9] Kayamori, Y. and Katayama, Y. (1994) A sensitive determination of uric acid in serum using uricase/ catalase/ formaldehyde dehydrogenase coupled with formate dehydrogenase. Clinical Biochemistry, 27, 93-97.

[10] Matsubara, C., Yokoi, Y., Nakamichi, N., Takamura, K. and Yakugaku, Z. (1994) Spectrophotometric determination of uric acid in serum using a titanium (IV)porphyrin complex. Journal of the Pharmaceutical Society of Japan, 114, 48-53.

[11] Fossati, P., Prencipe, L. and Berti, G. (1980) Use of 3, 5-dichloro-2-hydroxybenzenesulfonic acid/4-ami nophenazone chromogenic system in direct enzymic assay of uric acid in serum and urine. Clinical Chemistry, 26, 227-231. 
[12] Orsonneau, J.L., Massoubre, C., Cabanes, M. and Lustenberge, P. (1992) Simple and sensitive determination of urea in serum and urine. Clinical Chemistry, 38, 619623.

[13] Naslund, B., Sthale, U., Lundin, A., Anderstam, B., Arner, P. and Bergstrom, J. (1998) Luminometric single step urea assay using ATP-hydrolyzing urease. Clinical Chemistry, 44, 1964-1973.

[14] Rockwell, B.A., Roach, W.P., Rogers, M.E., Mayo, M.W., Toth, C.A., Cain, C.P. and Noojin, G.D. (1993) Nonlinear refraction in vitreous humor. Optics Letter, 18, 17921794.

[15] Arandi, G., Bezerra, Jr., Gomes, A.S.L., Celso P. de Melo. and Cid B. de Arafijo. (1997) Z-scan measurements of the nonlinear refraction in retinal derivatives. Chemical Physics Letters, 276, 445-449.

[16] Dhinaa, A.N., Ahmad, Y.N. and Palanisamy, P.K. (2008) Z-scan technique as a tool for the measurement of blood glucose. Laser Physics, 8, 1212-1216.

[17] Dhinaa, A.N. and Palanisamy, P.K. (2009) Z-scan technique for measurement of total cholesterol and triglycerides in blood. Journal of Innovative Optical Health Sciences, 2, 295-301.

[18] Sheik Bahae, M., Said, A.A., Wei, T.H., Hagan, D.J. and Vanstryland, E.W. (1990) Sensitive measurement of optical nonlinearities using a single beam. Quantum Elec- tron, 26, 760-769.

[19] Qusay, M.A. and Palanisamy, P.K. (2005) Investigation of nonlinear optical properties of organic dye by Z-scan technique using He-Ne laser. Optik, 116, 515-520.

[20] Madhanasundari, R. and Palanisamy, P.K. (2006) Optical nonlinearity of a triphenyl methane dye as studied by Z-scan and selfdiffraction techniques. Modern Physics Letter B, 20, 887-897.

[21] Qusay, M.A.and Palanisamy, P.K. (2006) Z-scan determination of the third order optical nonlinearity of organic dye nileblue chloride. Modern Physics Letter B, 20, 623632.

[22] Ahmad, Y.N., Dhinaa, A.N. and Palanisamy, P.K. (2007) Nonlinear optical properties of acid orange 10 dye by Z-scan technique using Ar+ laser. Journal of nonlinear Optical Physics and Materials, 16, 359-366.

[23] Taylor, A.J. and Vadgama, P. (1992) Analytical reviews in clinical biochemistry: the estimation of urea. Annals of Clinical Biochemistry, 29, 245-264.

[24] Fossati, P., Prencipe, L. and Berti, G. (1980) Use of 3,5-dichloro-2-hydroxybenzenesulfonic acid/4-aminophenazone chromogenic system in direct enzymic assay of uric acid in serum and urine. Clinical Chemistry, 26, 227-231. 